\title{
Intestinal metabolism of rye lignans in pigs
}

\author{
L. V. Glitsø $\emptyset^{1,2 *}$, W. M. Mazur ${ }^{3}$, H. Adlercreutz ${ }^{3}$, K. Wähälä ${ }^{4}$, T. Mäkelä ${ }^{4}$, B. Sandström ${ }^{2}$ \\ and K. E. Bach Knudsen ${ }^{1}$ \\ ${ }^{1}$ Danish Institute of Agricultural Sciences, Dept. of Animal Nutrition and Physiology, P.O. Box 50, Research Centre Foulum, \\ DK-8830 Tjele, Denmark \\ ${ }^{2}$ Research Dept. of Human Nutrition, The Royal Veterinary and Agricultural University, \\ DK-1958 Frederiksberg C, Denmark \\ ${ }^{3}$ Dept. of Clinical Chemistry, University of Helsinki and Folkhälsan Research Center, P.O. Box 60, \\ FIN-00014, University of Helsinki, Finland \\ ${ }^{4}$ Dept. of Chemistry, P.O. Box 55, O0014 University of Helsinki, Finland \\ (Received 6 April 1999 - Revised 19 November 1999 - Accepted 24 January 2000)
}

\begin{abstract}
To study the intestinal metabolism of lignans, the concentrations of plant and mammalian lignans in intestinal digesta sampled along the intestinal tract of pigs were determined by isotope dilution GC-MS. The pigs were fed rye-bread diets made from either whole rye-grains or rye-grain milling fractions enriched in pericarp-testa, aleurone or endosperm cells. The content and characteristics of dietary fibre varied between diets and had been shown to induce different colon fermentation patterns. As the metabolism of lignans depends on the action of the intestinal flora, we tested whether the rye-bread diets influence the metabolism of lignans. In the ileum, the lignans were mainly present as conjugated plant lignans, which were determined only when the analytical procedure included a hydrolysis step. High recovery of dietary lignans in the ileum may indicate that the lignans enter the enterohepatic circulation. In addition, two to three times the intake of lignans were recovered in the faeces when the diets had a high content of dietary fibre suggesting underestimation of plant lignans in the diet. Most of the plant lignans disappeared from the intestinal tract between the terminal ileum and the caecum. The intestinal concentrations and the disappearance of lignans correlated with the content of lignans in the diet, being highest on the pericarp-testa diet and lowest on the endosperm diet. No effect of fermentation pattern on the intestinal metabolism of lignans was observed. The lignans were liberated from the pericarp-testa diet although the plant cell walls remained largely undegraded.
\end{abstract}

Lignans: Colon fermentation: Dietary fibre

Plant phyto-oestrogens (lignans and isoflavonoids) have received considerable attention in recent years because it has been suggested that they may prevent breast and prostate cancer and perhaps also colon cancer (Adlercreutz, 1995; Knight \& Eden, 1996; Adlercreutz \& Mazur, 1997; Bingham et al. 1998; Murkies et al. 1998). Studies have shown that the urinary excretion of phyto-oestrogen metabolites is low in breast-cancer patients and high in vegetarians and Japanese people, both of which are populations with low risk of hormone-dependent cancers (Setchell \& Adlercreutz, 1988; Adlercreutz et al. 1995a). Soyabean products and legumes are the main sources of isoflavonoid phyto-oestrogens such as genistein and daidzein (Mazur et al. 1998). Plant lignans secoisolariciresinol (Seco) and matairesinol (Mata), the precursors of mammalian derivatives enterodiol (End) and enterolactone (Enl) respectively, occur as glycosides in wholegrain cereals, seeds, nuts, vegetables, berries and beverages such as tea and coffee (Adlercreutz, 1995; Mazur \& Adlercreutz, 1998).

Studies with germ-free rats (Axelson \& Setchell, 1981) and human subjects receiving antibiotics (Setchell et al. 1981) suggested that in order to exert their biological effects, the plant lignans have to be converted into mammalian lignans by microbial action (i.e. de-hydroxylation and de-methylation). Borriello et al. (1985) showed that viable bacteria from human faeces metabolised Seco and Mata into End and Enl respectively, and that End may be oxidised further to Enl. Nose et al. (1992) investigated the structural changes induced when incubating the lignans arctiin and tracheloside with colon content from the rat, and 
concluded that first the glycosidic lignans were deconjugated and then the aglycones were de-methylated. Unknown proportions of the mammalian lignans are absorbed from the lumen of the large intestine to the liver. Presumably the mammalian lignans are re-conjugated to glucuronides and sulfates in the intestinal wall and in the liver and excreted as such (Adlercreutz et al. 1995b). Axelson \& Setchell (1981) showed that in rats, part of the absorbed lignans entered the enterohepatic circulation and were re-excreted in the intestinal tract via the bile. Enterohepatic circulation of isoflavonoids has also been demonstrated by Sfakianos et al. (1997) in rats.

The need for conversion of the plant lignans by the colon flora suggests that the colon fermentation processes may play an important role for the metabolism and utilisation of lignans. There is, however, very limited information on the level of plant and mammalian lignans in digesta material, or on how the mode of fermentation in the large intestine influences the conversion from plant to mammalian lignans. In the present investigation we determined, therefore, the concentration of plant and mammalian lignans in digesta from the ileum, the caecum, the middle colon and in faeces from pigs that were fed breads based on whole-rye grains and three rye-grain milling fractions. These diets have previously been shown to vary significantly in composition and characteristics of dietary fibre and subsequently in the mode of fermentation in the large intestine (Glits $\varnothing$ et al. 1998; Glits $\varnothing$ \& Bach Knudsen, 1999). Animal models allow sampling of material from different parts of the intestinal tract. The pig was chosen as animal model as the morphology and physiology of the gastrointestinal system of the pig is comparable with that of human subjects in many respects (Stevens et al. 1986; Miller \& Ullrey 1987; Rowan et al. 1994).

\section{Materials and methods}

\author{
Rye diets
}

Rye (Secale cereale L., cv. Marder, Bornholm, Denmark, 1993) was separated by dry-milling into three fractions enriched in cell tissue from pericarp-testa, the aleurone layer, and endosperm (Glits $\varnothing$ \& Bach Knudsen, 1999). Rye breads based on whole rye-grain and rye-grain milling fractions were produced in an industrial bakery (Pandrup Brød, Schulstad A/S, Pandrup, Denmark) (Glits $\varnothing$ \& Bach Knudsen, 1999). Wheat-starch, casein, gluten, lard, vegetable oil, vitamins, minerals, yeast and water were added to the rye raw materials. The diets were formulated to give an energy contribution from fat, protein and available carbohydrates of approximately 25, 15 and $60 \%$ respectively. The four breads were balanced with regard to fat, protein, starch, minerals and vitamins but varied in source and hence characteristics of cell walls. The level of dietary fibre (sum of NSP and lignin) was kept constant in the whole rye, pericarp-testa and aleurone diets, but it was not possible to raise the level of dietary fibre in the endosperm bread to that of the others due to the low concentration of dietary fibre in the endosperm milling fraction. $\mathrm{Cr}_{2} \mathrm{O}_{3}$ was added to the diets as an indigestible marker (see Table 1 for diet ingredients and composition).

\section{Animal experiments}

Twenty growing male castrated pigs (five pigs per diet; weight at surgery approximately $30 \mathrm{~kg}$; Danish Institute of Agricultural Sciences Swine herd, Foulum, Denmark) were fitted with simple T-cannulas approximately $15 \mathrm{~cm}$ anterior to the ileo-caecal junction and allowed to recover

Table 1. Ingredients ( $\mathrm{g} / \mathrm{kg}$ diet) and composition ( $\mathrm{g} / \mathrm{kg} \mathrm{DM}$ ) of rye-bread diets

\begin{tabular}{|c|c|c|c|c|}
\hline Diet ... & Whole rye & Pericarp-testa & Aleurone & Endosperm \\
\hline \multicolumn{5}{|l|}{ Ingredients ( $\mathrm{g} / \mathrm{kg}$ diet) } \\
\hline Rye raw material ${ }^{*}$ & 866 & 213 & 591 & 762 \\
\hline Wheat starch & - & 546 & 277 & - \\
\hline Casein & 26 & 112 & 28 & 104 \\
\hline Gluten & 9.5 & $9 \cdot 6$ & 9.5 & 9.5 \\
\hline Soyabean oil & 35 & 46 & 33 & 49 \\
\hline Lard & 29 & 38 & 27 & 41 \\
\hline Baker's yeast & $7 \cdot 1$ & $7 \cdot 2$ & $7 \cdot 1$ & $7 \cdot 1$ \\
\hline Vitamin-mineral mixture $\dagger$ & 26 & 27 & 26 & 26 \\
\hline $\mathrm{Cr}_{2} \mathrm{O}_{3}$ & 0.77 & 0.87 & 0.80 & 0.77 \\
\hline \multicolumn{5}{|l|}{ Composition (g/kg DM) } \\
\hline Protein & 133 & 144 & 148 & 174 \\
\hline Fat & 94 & 106 & 99 & 103 \\
\hline Starch & 519 & 503 & 471 & 559 \\
\hline \multicolumn{5}{|l|}{ Non-starch polysaccharides: } \\
\hline Cellulose & 14 & 31 & 14 & 12 \\
\hline Arabinoxylans $\ddagger$ & $74(37)$ & $85(4)$ & $87(28)$ & $31(66)$ \\
\hline Arabinose: xylose & 0.66 & 1.04 & 0.42 & 0.75 \\
\hline Total non-starch polysaccharides $\ddagger$ & $136(29)$ & $153(5)$ & $150(25)$ & 77 (39) \\
\hline Klason lignin & 21 & 24 & 27 & 16 \\
\hline Dietary fibre§ & 157 & 177 & 177 & 93 \\
\hline
\end{tabular}

* Whole rye, pericarp-testa, aleurone or endosperm, respectively.

† Containing $\mathrm{Ca}_{2}\left(\mathrm{PO}_{4}\right)_{3}, \mathrm{~K}_{2} \mathrm{PO}_{3}, \mathrm{NaCl}, \mathrm{CaCO}_{3}$ and a commercial mixture of vitamins and minerals to pig feed (Solivit Mikro 106, Løvens Kemiske Fabrik, Vejen, Denmark).

$\ddagger$ Values in parentheses are soluble matter (phosphate buffer $\mathrm{pH} 7 ; 100^{\circ} \mathrm{C}, 60 \mathrm{~min}$ ) expressed as a percentage of total matter.

$\S$ Sum of non-starch polysaccharides and Klason lignin. 
for $8-10 \mathrm{~d}$. After an adaptation period of $8-9 \mathrm{~d}$ on the experimental diets, the pigs were placed in metabolic cages (balance period) and faeces were collected for $72 \mathrm{~h}$. Following the faecal collection, ileal contents were sampled from the cannulas from 07.00 to 15.00 hours starting at the time of the morning feeding, and this was repeated $2 \mathrm{~d}$ later. The ileal collections were performed by attaching small plastic tubes to the cannula. The tubes were emptied either when they were full or they were emptied if they had been attached for $90 \mathrm{~min}$. The pigs rested for 1 week still consuming the experimental diets and were then subjected to a similar second balance period in the metabolic cages. The pigs were slaughtered 3-4d after the last balance period by an overdose of pentobarbital $4 \mathrm{~h}$ post-feeding. The gastrointestinal tract was immediately removed and intestinal material was collected from the caecum, the middle third of the colon, and rectum. Freeze-dried intestinal samples were analysed for lignans. All aspects of this protocol were approved by the Danish Animal Experiments Inspectorate, Copenhagen, Denmark.

\section{Analytical methods}

All analyses were performed at least in duplicate on raw or freeze-dried material. All samples were ground to a particle size $<0.5 \mathrm{~mm}$ prior to analysis. The DM content was determined by drying the samples at $105^{\circ} \mathrm{C}$ for $20 \mathrm{~h}$. Food samples were hydrolysed with an enzyme mixture (containing $\beta$-glucuronidase, sulfatase and other minor enzyme activities extracted from the digestive juice of the Burgundy snail (Helix pomatia)) and $\mathrm{HCl}$, extracted with diethyl ether and subsequently purified and separated on DEAE- and QAE-Sephadex columns (Pharmacia Five Chemicals, Uppsala, Sweden) according to Mazur et al. (1996). Free and hydrolysed conjugates of the plant lignans Seco and Mata were derivatised to form trimethylsilyl ethers and analysed by isotope dilution GC-MS in the selected ionmonitoring mode using synthesised ${ }^{2} \mathrm{H}$-labelled internal standards for the correction of losses during the procedure. All raw material and dietary samples were additionally hydrolysed with trifluoroacetic acid $\left(\mathrm{C}_{2} \mathrm{HF}_{3} \mathrm{O}_{2}\right)$ in a parallel experiment in order to check whether trifluoroacetic-acid hydrolysis would be more efficient in liberating the plant (dietary) lignans Seco and Mata from the matrix compared with the $\mathrm{HCl}$ hydrolysis used in the original method (Mazur et al. 1996). The modified method consisted of the same steps as the original one, but the conditions at the most critical phase of the method, i.e. the acid hydrolysis, were different $\left(2 \mathrm{M}^{-\mathrm{C}_{2}} \mathrm{HF}_{3} \mathrm{O}_{2}, 120^{\circ} \mathrm{C}, 2.5 \mathrm{~h}\right.$ v. $2 \mathrm{M}-\mathrm{HCl}, 100^{\circ} \mathrm{C}$, $2.5 \mathrm{~h}$ in the original method). Food samples are not expected to contain End or Enl (W Mazur and H Adlercreutz, unpublished results) and thus these compounds were not included in the analysis on food samples.

Following the addition of ${ }^{2} \mathrm{H}$-labelled internal standards for all compounds, the intestinal samples were extracted and purified in several ion-exchange chromatographic steps according to Adlercreutz et al. (1995a). Using this methodology, only unconjugated lignans Seco, Mata, End and Enl were extracted from the intestinal samples and, following derivatisation, measured by isotope dilution $\mathrm{GC}-\mathrm{MS}$ in the selected ion-monitoring mode. The results were corrected for losses during all the purification steps. Ileal samples were additionally hydrolysed with acid and analysed with a combination of both the methods for food samples and faeces. Briefly, the ileum samples were treated, according to Adlercreutz et al. (1995a), with distilled water-acetone $(1: 1, \mathrm{v} / \mathrm{v})$, extracted with absolute ethanol and filtered. The samples were then centrifuged and residues were discarded while supernatants were extracted with ether as in the method for dietary samples (free fraction). Subsequently, the water phase after ether extraction was hydrolysed with $2 \mathrm{~mol} \mathrm{HCl} / \mathrm{l}$ (conjugates) and the following steps were identical to those in the method of Mazur et al. (1996). Measurements of the plant and mammalian lignans (total conjugates and unconjugated lignans) liberated by this combined methodology were finally performed using isotope-dilution GC-MS in the ion-monitoring mode. ${ }^{2} \mathrm{H}$ labelled internal standards of all the compounds were used for the correction of losses during the procedure. $\mathrm{Cr}_{2} \mathrm{O}_{3}$ was analysed by colorimetry using the method of Schürch et al. (1950). Starch was determined enzymatically and the cellwall monosaccharide components were determined as alditol acetates by GLC as described in details by Bach Knudsen (1997). Arabinoxylans were calculated as the sum of anhydrous arabinose and xylose monomers.

\section{Calculations}

The theoretical content of lignans in the diets on the basis of the concentration of lignans in the rye raw materials $\left(\right.$ Calc $\left._{\text {lignan }}\right)$ was calculated using arabinoxylans as an internal marker for the rye raw materials, and thus assuming that the lignans: arabinoxylans ratio was the same in the rye raw materials and in the corresponding diets:

$$
\text { Calc }_{\text {lignan }}=\frac{\text { Lignan }_{\text {raw }} \times A X_{\text {diet }}}{A X_{\text {raw }}},
$$

where Lignan $_{\text {raw }}$ and $A X_{\text {raw }}$ are the concentrations of plant lignans and arabinoxylans in the raw material respectively, and $A X_{\text {diet }}$ is the concentration of arabinoxylans in the diet. In order to test this method of calculation, the theoretical content of starch from the rye raw materials to the rye diets $\left(\right.$ Calc $\left._{\text {starch }}\right)$ was calculated using a similar formula:

$$
\text { Calc }_{\text {starch }}=\frac{\text { Starch }_{\text {raw }} \times A X_{\text {diet }}}{A X_{\text {raw }}},
$$

where Starch $_{\text {raw }}$ is the concentration of starch in the raw material.

Recovery of the dietary plant lignans ( $R_{\text {diet }} ; \%$ of intake) as plant and mammalian lignans in the intestinal segments were calculated as shown in the following example for a caecum sample $\left(R_{\text {diet(caecum })}\right)$ :

$$
R_{\text {diet(caecum) }}=\frac{\text { Lignan }_{\text {caecum }} \times \mathrm{Cr}_{2} \mathrm{O}_{3 \text { diet }} \times 100}{\text { Lignan }_{\text {diet }} \times \mathrm{Cr}_{2} \mathrm{O}_{3 \text { caecum }}},
$$

where Lignan $_{\text {caecum }}$ is the concentration of plant and mammalian lignans in the caecum sample and Lignan $_{\text {diet }}$ is the concentration of plant lignans determined in the diet and $\mathrm{Cr}_{2} \mathrm{O}_{3}$ diet and $\mathrm{Cr}_{2} \mathrm{O}_{3}$ caecum are the concentrations of $\mathrm{Cr}_{2} \mathrm{O}_{3}$ in diet and caecum respectively. 
Similarly, the recovery of ileal lignans $\left(R_{\text {ileum }} ; \%\right.$ of ileal level) in the large intestine was calculated as shown in the following example for a caecum sample $\left(R_{\text {ileum(caecum })}\right)$ :

$$
R_{\text {ileum }(\text { caecum })}=\frac{\text { Lignan }_{\text {caecum }} \times \mathrm{Cr}_{2} \mathrm{O}_{3 \text { ileum }} \times 100}{\text { Lignan }_{\text {ileum }} \times \mathrm{Cr}_{2} \mathrm{O}_{3 \text { caecum }}},
$$

where Lignan $_{\text {ileum }}$ and $\mathrm{Cr}_{2} \mathrm{O}_{3}$ ileum are the concentrations of lignans and $\mathrm{Cr}_{2} \mathrm{O}_{3}$ in the ileum respectively.

The daily recovery of dietary lignans in the ileum $\left(R_{\text {daily(ileum })} ; \mu \mathrm{mol} / \mathrm{d}\right)$ was calculated as:

$$
R_{\text {daily(ileum) }}=\frac{\text { Lignan }_{\text {daily intake }} \times R_{\text {diet(ileum })}}{100},
$$

where Lignan daily intake is the average daily intake of lignans at time of slaughtering (see Table 2).

The disappearance of lignans from the intestinal tract between the ileum and the caecum $\left(\right.$ Dis $_{\text {ileum }}$ - caecum $)$ was calculated as:

$$
\text { Dis }_{\text {ileum }- \text { caecum }}=R_{\text {daily }(\text { ileum })}-\frac{R_{\text {daily(ileum })} \times R_{\text {ileum }(\text { caecum })}}{100} .
$$

\section{Statistical methods}

Values are expressed as means with standard errors of the means. The data were analysed using one-way ANOVA (Table 2) and two-way ANOVA (Table 3). Duncan's multiple range test was used to determine whether mean values were significantly different. Correlation coefficients for relationships between unconjugated lignans and conjugated lignans or recovery of dietary lignans in ileum (Table 2) were assessed using the least squares method (Pearson). Subsequently, the Pearson method was used to test correlation coefficients for plant and mammalian lignans, and recovery of dietary lignans or recovery of ileal lignans (Table 3). The differences were considered significant at $P<$ 0.05. All the statistical analyses were performed using the
SPSS package program, ver. 6.1J (SPSS Inc., Chicago, IL, USA).

\section{Results \\ Concentration of plant lignans in rye raw materials and rye diets}

In the raw materials, the highest concentration of plant lignans was found in the pericarp-testa sample $(5.0 \mathrm{nmol} /$ g DM) (Table 4), the content was intermediate in the aleurone raw material $(2.9 \mathrm{nmol} / \mathrm{g} \mathrm{DM})$ and lowest in the endosperm $(0.5 \mathrm{nmol} / \mathrm{g} \mathrm{DM})$. The total concentration of plant lignans was comparable between the whole rye, aleurone and endosperm diets $(2.4-3.5 \mathrm{nmol} / \mathrm{g} \mathrm{DM})$, but considerably higher in the pericarp-testa diet $(10.3 \mathrm{nmol} / \mathrm{g}$ DM). Concentrations of lignans obtained using the modified food method (i.e. trifluoroacetic acid hydrolysis) were the same or slightly higher than the results of the standard $\mathrm{HCl}$ hydrolysis method (results not shown).

Using the lignan content of the rye raw materials, the theoretical contents of plant lignans in the rye diets were calculated. The calculated contents were considerably lower than the contents of lignans measured in the diets and this was particularly evident for the pericarp-testa diet. The theoretical starch content in the rye diets was also calculated for the whole rye and endosperm diets where the starch originated only from the rye raw materials. The calculated starch concentrations were 530 and $590 \mathrm{~g} / \mathrm{kg}$ DM for the whole rye and endosperm diets respectively, compared with 530 and $580 \mathrm{~g} / \mathrm{kg}$ DM as analysed in the two diets.

\section{Concentration of plant and mammalian lignans in intestinal samples}

Irrespective of diet, the concentration of total lignans (plant and mammalian) was highest in the ileum samples and at this site, the majority of the lignans were conjugated. Concentration of conjugated lignans thus ranged from

Table 2. Concentration ( $\mathrm{nmol} / \mathrm{g} \mathrm{DM})$ of unconjugated and conjugated lignans in the ileum, daily intake $(\mu \mathrm{mol} / \mathrm{d})$ of plant lignans and the recovery

\begin{tabular}{|c|c|c|c|c|c|c|c|c|c|c|c|c|}
\hline \multirow[b]{3}{*}{ Diet† } & \multicolumn{4}{|c|}{ Unconjugated lignans* } & \multicolumn{4}{|c|}{ Conjugated lignans* } & \multirow{3}{*}{$\begin{array}{c}\text { Daily intake } \\
\text { of plant } \\
\text { lignans } \\
(\mu \mathrm{mol} / \mathrm{d})\end{array}$} & \multicolumn{3}{|c|}{$\begin{array}{l}\text { Ileal recovery of dietary } \\
\text { lignans }\end{array}$} \\
\hline & \multicolumn{2}{|c|}{$\mathrm{nmol} / \mathrm{g}$ DM } & \multicolumn{2}{|c|}{$\%$ mam $^{\star}$} & \multicolumn{2}{|c|}{$\mathrm{nmol} / \mathrm{g}$ DM } & \multicolumn{2}{|c|}{$\%$ mam $^{*}$} & & \multicolumn{2}{|c|}{$\%$} & \multirow{2}{*}{$\frac{\mu \mathrm{mol} / \mathrm{d}}{\text { Mean }}$} \\
\hline & Mean & SEM & Mean & SEM & Mean & SEM & Mean & SEM & & Mean & SEM & \\
\hline Whole rye & $2 \cdot 1^{a b}$ & 0.7 & 21 & 7 & $73 \cdot 0^{a}$ & 15 & $3 \cdot 1$ & 1.0 & 3.6 & 1052 & 304 & 38 \\
\hline Pericarp-testa & $3 \cdot 3^{b}$ & 0.3 & 29 & 6 & $310 \cdot 4^{b}$ & 78 & 2.4 & 0.6 & $15 \cdot 5$ & 959 & 260 & 149 \\
\hline Aleurone & $2 \cdot 5^{b}$ & 0.8 & 21 & 9 & $98.0^{a}$ & 38 & $4 \cdot 8$ & 1.0 & $5 \cdot 1$ & 961 & 409 & 49 \\
\hline Endosperm & $0 \cdot 6^{a}$ & 0.1 & 42 & 15 & $34 \cdot 8^{a}$ & 7.5 & 3.7 & 0.2 & 3.6 & 251 & 51 & 9 \\
\hline \multicolumn{13}{|c|}{ Statistical significance } \\
\hline (ANOVA): $P$ & \multicolumn{2}{|c|}{$<0.05$} & \multicolumn{2}{|c|}{ NS } & \multicolumn{2}{|c|}{$<0.05$} & \multicolumn{2}{|c|}{ NS } & & \multicolumn{2}{|c|}{ NS } & \\
\hline
\end{tabular}
$(\%$ and $\mu \mathrm{mol} / \mathrm{d})$ of dietary lignans in the ileum in pigs fed diets containing whole rye or rye milling fractions

(Mean values with standard errors of the mean for five pigs per diet group)

mam, mammalian lignans.

${ }_{a, b}$ Mean values within a column with unlike superscript letters were significantly different $(P<0.05)$.

${ }^{*}$ Conjugated and unconjugated lignans as sum of plant (secoisolariciresinol and matairesinol) and mammalian (enterodiol and enterolactone) lignans, and mammalian lignans as a percentage of total lignans.

$\dagger$ For details of diets see Table 1.

$\ddagger$ Calculated using the average feed intake at time of slaughtering $(1500 \mathrm{~g} \mathrm{DM} / \mathrm{d}$; average weight of pigs at slaughter $53 \mathrm{~kg})$. 
Table 3. Concentration ( $\mathrm{nmol} / \mathrm{g}$ DM) of unconjugated plant* and mammalian† lignans and recovery (\%) of dietary and ileal lignans in segments of the large intestine in pigs fed diets containing whole rye or rye milling fractions

(Mean values with standard errors of the means for five pigs per diet group)

\begin{tabular}{|c|c|c|c|c|c|c|c|c|c|c|}
\hline \multirow[b]{2}{*}{ Dietł } & \multirow{2}{*}{$\begin{array}{l}\text { Intestinal } \\
\text { segment }\end{array}$} & \multirow[b]{2}{*}{$n$} & \multicolumn{2}{|c|}{$\begin{array}{c}\text { Plant } \\
\text { lignans } \\
(\mathrm{nmol} / \mathrm{g} \text { DM) }\end{array}$} & \multicolumn{2}{|c|}{$\begin{array}{c}\text { Mammalian } \\
\text { lignans } \\
\text { (nmol/g DM) }\end{array}$} & \multicolumn{2}{|c|}{$\begin{array}{l}\text { Recovery of } \\
\text { dietary lignans } \\
(\%) \S\end{array}$} & \multicolumn{2}{|c|}{$\begin{array}{l}\text { Recovery of } \\
\text { ileal lignans } \\
\qquad(\%)\end{array}$} \\
\hline & & & Mean & SEM & Mean & SEM & Mean & SEM & Mean & SEM \\
\hline \multirow[t]{3}{*}{ Whole rye } & Caecum & 3 & $4.9^{b}$ & 1.4 & $32^{a}$ & 14 & $306^{b}$ & 105 & 42 & $\overline{18}$ \\
\hline & Middle colon & 5 & $0.3^{a}$ & 0.1 & $46^{a}$ & $2 \cdot 8$ & $288^{b}$ & 15 & 36 & 9 \\
\hline & Faeces & 5 & $0.1^{a}$ & 0.1 & $55^{\mathrm{a}}$ & 8.6 & $306^{\mathrm{bc}}$ & 55 & 37 & 10 \\
\hline \multirow[t]{3}{*}{ Pericarp-testa } & Caecum & 4 & $4 \cdot 9^{b}$ & 1.7 & $42^{a}$ & 3.9 & $131^{\mathrm{a}}$ & 6 & 21 & 8 \\
\hline & Middle colon & 5 & $0.6^{\mathrm{a}}$ & 0.2 & $85^{b}$ & 21 & $210^{b}$ & 52 & 33 & 13 \\
\hline & Faeces & 5 & $0.3^{a}$ & 0.1 & $99^{b}$ & 25 & $216^{c}$ & 52 & 35 & 14 \\
\hline \multirow[t]{3}{*}{ Aleurone } & Caecum & 5 & $8.5^{c}$ & 1.4 & $16^{\mathrm{a}}$ & 3.7 & $176^{a}$ & 22 & 31 & 6 \\
\hline & Middle colon & 6 & $1.2^{\mathrm{a}}$ & 0.5 & $48^{a}$ & 6.9 & $275^{\mathrm{b}}$ & 45 & 36 & 8 \\
\hline & Faeces & 6 & $0.2^{a}$ & 0.2 & $72^{\mathrm{a}}$ & 6.9 & $360^{\mathrm{b}}$ & 34 & 51 & 13 \\
\hline \multirow[t]{3}{*}{ Endosperm } & Caecum & 2 & $4 \cdot 5^{\mathrm{b}}$ & 0.1 & $14^{a}$ & 8.6 & $86^{a}$ & 24 & 29 & 3 \\
\hline & Middle colon & 5 & $0.2^{\mathrm{a}}$ & 0.1 & $12^{\mathrm{a}}$ & 3.6 & $42^{\mathrm{a}}$ & 10 & 16 & 1 \\
\hline & Faeces & 4 & $0 \cdot 1^{a}$ & 0.1 & $19^{a}$ & 4.8 & $49^{a}$ & 13 & 19 & 2 \\
\hline \multicolumn{11}{|c|}{$\begin{array}{l}\text { Statistical significance of effect } \\
\text { (two-way ANOVA): } P \\
\text { Main effect }\end{array}$} \\
\hline \multicolumn{3}{|l|}{ Diet (D) } & \multicolumn{2}{|c|}{$<0.01$} & \multicolumn{2}{|c|}{$<0.001$} & \multicolumn{2}{|c|}{$<0.001$} & \multicolumn{2}{|c|}{ NS } \\
\hline \multicolumn{3}{|l|}{ Intestinal segment (S) } & \multicolumn{2}{|c|}{$<0.001$} & \multicolumn{2}{|c|}{$<0.01$} & \multicolumn{2}{|c|}{ NS } & \multicolumn{2}{|c|}{ NS } \\
\hline Interaction $\mathrm{D} \times \mathrm{S}$ & & & \multicolumn{2}{|c|}{ NS } & \multicolumn{2}{|c|}{ NS } & \multicolumn{2}{|c|}{ NS } & \multicolumn{2}{|c|}{ NS } \\
\hline
\end{tabular}

Mean values within a column with unlike superscript letters were significantly different $(P<0.05)$.

* Secoisolariciresinol and matairesinol.

$\dagger$ Enterodiol and enterolactone.

$\ddagger$ For details of diets see Table 1 .

$\S$ Statistical difference analysed for the same segment of different diets.

$34.8 \mathrm{nmol} / \mathrm{g}$ DM in the ileum of the endosperm-fed pigs to $310.4 \mathrm{nmol} / \mathrm{g}$ DM in the ileum of the pericarp-testa-fed pigs compared with a range of 0.6 to $3.3 \mathrm{nmol}$ unconjugated lignans/g DM (Table 2). More than $95 \%$ of the conjugated lignans in the ileum were plant lignans, while the mammalian lignans constituted a greater percentage of the unconjugated lignans $(21-42 \%)$.
In the samples from the large intestine only the unconjugated lignans were determined. The concentration of plant lignans decreased markedly from the ileum to the caecum, whereas the concentration of mammalian lignans increased in the caecum samples and further in the middle colon or faeces for the pigs fed the pericarp-testa or the aleurone diets respectively (Table 3 ). The faecal concentration of

Table 4. Plant lignans* $(\mathrm{nmol} / \mathrm{g} \mathrm{DM})$, starch and arabinoxylans in raw materials and rye diets, and theoretical content of lignans and starch in the diets based on the content in the rye raw materials $\dagger$

\begin{tabular}{|c|c|c|c|c|c|c|c|}
\hline & \multicolumn{5}{|c|}{$\begin{array}{l}\text { Plant lignans } \\
\text { (nmol/g DM) }\end{array}$} & \multirow{2}{*}{$\begin{array}{c}\mathrm{AX} \\
(\mathrm{g} / \mathrm{kg} \mathrm{DM})\end{array}$} & \multirow{2}{*}{$\begin{array}{c}\text { Starch } \\
(g / \mathrm{kg} \mathrm{DM})\end{array}$} \\
\hline & $n$ & Seco & Mata & Lignans & SEM lignans & & \\
\hline \multicolumn{8}{|l|}{ Raw materials } \\
\hline Whole rye & 2 & 0.9 & 0.4 & 1.3 & 0.2 & 90 & 630 \\
\hline Pericarp-testa & 2 & $2 \cdot 2$ & 2.9 & $5 \cdot 0$ & 0.7 & 395 & - \\
\hline Aleurone & 2 & 1.8 & $1 \cdot 1$ & $2 \cdot 9$ & 0.2 & 163 & - \\
\hline Endosperm & 2 & 0.3 & 0.1 & 0.5 & 0.2 & 42 & 790 \\
\hline \multicolumn{8}{|c|}{ Diet (analysed content) } \\
\hline Whole rye & 4 & 1.5 & 0.9 & $2 \cdot 4$ & 0.7 & 75 & 530 \\
\hline Pericarp-testa & 10 & $9 \cdot 1$ & 1.1 & $10 \cdot 3$ & 3.5 & 85 & - \\
\hline Aleurone & 4 & $2 \cdot 6$ & 0.8 & 3.4 & 0.9 & 88 & - \\
\hline Endosperm & 4 & $2 \cdot 1$ & 0.2 & $2 \cdot 4$ & 0.8 & 31 & 580 \\
\hline \multicolumn{8}{|c|}{ Diet (theoretical content)‡ } \\
\hline Whole rye & & 0.8 & 0.3 & $1 \cdot 1$ & - & - & 530 \\
\hline Pericarp-testa & & 0.5 & 0.6 & $1 \cdot 1$ & - & - & - \\
\hline Aleurone & & 1.0 & 0.6 & 1.6 & - & - & - \\
\hline Endosperm & & 0.2 & 0.1 & 0.3 & - & - & 590 \\
\hline
\end{tabular}

Seco, secoisolariciresinol; Mata, matairesinol; AX, arabinoxylans.

* Secoisolariciresinol and matairesinol.

†For details of diets see Table 1.

$\ddagger$ Theoretical content in the diets based on the content in the rye raw materials (calculated using the AX content as an internal marker). 
Table 5. Faecal excretion relative to intake of dietary fibre ( $\mu \mathrm{mol} / \mathrm{g}$ dietary fibre) in pigs ( $n 5$ per diet group) fed the rye-bread diets and in human subjects (omnivorous and vegetarian)*

\begin{tabular}{|c|c|c|c|c|c|}
\hline Diet† & & $\begin{array}{l}\text { Faecal excretion } \\
\text { of lignans } \\
(\mu \mathrm{mol} / \mathrm{d})\end{array}$ & $\begin{array}{l}\text { Stool weight } \\
(\mathrm{g} / \mathrm{d})\end{array}$ & $\begin{array}{l}\text { Intake of } \\
\text { dietary fibre } \\
(\mathrm{g} / \mathrm{d})\end{array}$ & $\begin{array}{c}\text { Faecal excretion of lignans } \\
\text { per intake of dietary fibre } \\
\text { ( } \mu \mathrm{mol} / \mathrm{g} \text { dietary fibre })\end{array}$ \\
\hline Pigs & $\begin{array}{l}\text { Whole rye } \\
\text { Pericarp-testa } \\
\text { Aleurone } \\
\text { Endosperm }\end{array}$ & $\begin{array}{c}11 \\
33 \\
18 \\
1.8\end{array}$ & $\begin{array}{r}599 \\
1200 \\
875 \\
231\end{array}$ & $\begin{array}{l}236 \\
266 \\
266 \\
140\end{array}$ & $\begin{array}{l}0.05 \\
0.12 \\
0.07 \\
0.01\end{array}$ \\
\hline Human subjects & $\begin{array}{l}\text { Omnivorous } \\
\text { Vegetarian }\end{array}$ & $\begin{array}{l}1.7 \\
3.9\end{array}$ & $\begin{array}{l}148 \\
223\end{array}$ & $\begin{array}{l}19 \ddagger \\
23\end{array}$ & $\begin{array}{l}0.09 \\
0.17\end{array}$ \\
\hline
\end{tabular}

* Data on human subjects adapted from Adlercreutz et al. (1986, 1995a).

$\dagger$ For details of diets see Table 1.

¥Average intake over 1 year (intake in winter $18 \mathrm{~g} / \mathrm{d}$ and in summer $20 \mathrm{~g} / \mathrm{d}$ ).

mammalian lignans was thus significantly higher for the pigs fed the pericarp-testa or the aleurone diets compared with the other pigs (72-99 v. $19-55 \mathrm{nmol} / \mathrm{g} \mathrm{DM})$.

\section{Recovery of plant lignans in intestinal samples}

The daily intake of lignans at the time of slaughtering was $15.5 \mu \mathrm{mol} / \mathrm{d}$ with the pericarp-testa diet and 3.6-5.1 $\mu \mathrm{mol} /$ $\mathrm{d}$ with the other diets (Table 2). The ileal recovery of dietary lignans ranged from $251 \%$ (in pigs fed the endosperm diet) to $1052 \%$ (in the pigs fed the whole-rye diet), which means that at least twice as many lignans as had been ingested were recovered in the ileum of the pigs. These recoveries corresponded to a daily recovery in the ileum of $9-149 \mu \mathrm{mol} / \mathrm{d}$.

Table 3 shows the recovery of both dietary and ileal lignans in the large intestine. Approximately half of the ingested endosperm lignans were recovered in faeces, whereas two to three times as many lignans as had been ingested were recovered in the faeces of the pigs fed the three other diets (i.e. recoveries ranged from 216 to $360 \%$ ). In the caecum, the recovery of ileal lignans ranged from $21 \%$ in the pericarp-testa sample to $42 \%$ in the whole rye, which may indicate that the majority of ileal lignans disappeared from the lumen before the caecum. There was no significant effect of diet on the recovery of ileal lignans in the colon.

\section{Discussion}

\section{Plant lignans in rye raw materials and rye diets}

Nilsson et al. (1997) determined the concentrations of lignans in rye milling fractions and showed that the highest content was present in the bran. This was also the case in the present study, which further showed that the concentration of lignans was higher in the pericarp-testa than in the aleurone. In the rye diets, the lignan concentrations were two to nine times higher than expected on the basis of the content in the rye raw materials; and the good agreement between the calculated and measured starch concentrations in the whole-rye and endosperm diets showed that this was not merely due to the insecurities of the calculation. The largest difference between the theoretical lignan concentration and the actual concentration was observed in the pericarp-testa diet, where the lignan concentration was nine times higher than the theoretical concentration. To confirm the analysis of the first four subsamples of the pericarp-testa diet samples, the measurements were repeated on another six subsamples and the results remained high.

A higher concentration in the diets relative to the raw materials was expected as other of the rye-bread ingredients (Table 1) may contain lignans too. The other diet ingredients were not analysed for lignans, but based on our previous studies wheat flour contains approximately $0.22 \mathrm{nmol}$ lignans $/ \mathrm{g}$ and soyabean oil approximately $0.03 \mathrm{nmol} / \mathrm{g}$ (Adlercreutz \& Mazur, 1997). Assuming a similar concentration in the wheat starch as in the wheat flour, this would account for approximately $0.12 \mathrm{nmol} / \mathrm{g}$ DM for the pericarptesta diet and $0.06 \mathrm{nmol} / \mathrm{g}$ DM for the aleurone diet. This corresponds to approximately $10 \%$ and $3 \%$ of the lignans derived from the pericarp-testa and aleurone raw materials (i.e. of the theoretical contents of lignans) respectively. However, the contributions of lignans from the wheat flour are small compared with the discrepancies between the lignans in the rye raw materials and the rye diets. The contribution from the soyabean oil is even smaller and also cannot explain the discrepancy. The reason for this large increase in lignan concentration from the pericarp-testa raw material to the pericarp-testa bread is not known, but it can be speculated that it is due to the cell wall structure and the linkages between cell wall components in the high-fibre raw materials, such as pericarp-testa, which may not be broken during acid hydrolysis. Like other cell-wall esterified phenolic compounds (Eraso \& Hartley, 1990), dimers, trimers and higher oligomers of the lignans may occur (Anderegg \& Rowe, 1974; Ayres \& Loike, 1990) and these probably contain ether bonds not broken in the method used. However, the activity of yeast or the baking procedure itself may potentially have made a bigger fraction of the lignans in the pericarp-testa raw material available for the acid hydrolysis. High temperatures applied at the baking process (reaching $260^{\circ} \mathrm{C}$ in the oven) may have destroyed bonds in possible poly- and/or oligomeric lignans or liberated yet unknown mammalian lignan precursors from the aleurone or pericarp-testa cell matrix. H Härkönen, $M$ Nilsson, $\mathrm{P}$ Åman, G Hallmans KE Bach Knudsen and H Adlercreutz (unpublished results) did not observe changes in the lignan content during the baking procedure of rye bread, however, but only whole-rye bread was tested in that experiment. 
It should be noted, in addition, that there were large variations in the determinations of plant lignans in the diets. This may in part be due to the difficulty of taking a small sample $(20-50 \mathrm{mg})$ representatively from a rye bread, even when it is freeze-dried and ground.

\section{Lignan metabolism in the intestinal tract of pigs}

In contrast to the method for food material (Mazur et al. 1996), conjugated lignans (glucuronides, glucosides and sulfates) were not measured in the faeces method (which was used to analyse all the intestinal samples) as more than $90 \%$ are believed to be deconjugated in the faeces (Adlercreutz et al. 1995a) and consequently the method did not include a hydrolysis step. In the present study, the ileal samples were also analysed by a combined method, which included the acid $(\mathrm{HCl})$ hydrolysis step (originally in the food method only) in the analysis of the ileal content, thus making it possible to determine both unconjugated and conjugated lignans present in the ileum. The results clearly showed that the majority $(>95 \%)$ of lignans present in the ileum were conjugated, and hence hydrolysis is needed to determine the content of lignans in ileal material. In the ileum of pigs, the microbial activity is low compared with that in the caecum (Bach Knudsen et al. 1993), and bacterial growth rates and activities (e.g. reductive, oxidative and hydrolytic reactions) are also greatest in the right colon of human subjects (Cummings \& MacFarlane, 1991). It was therefore assumed that the samples from the caecum and middle colon would be deconjugated by the microbial enzymes. The results on the ileal samples suggested that the initial deconjugation of plant lignans carried out by the microflora (Nose et al. 1992) had not yet occurred in the ileum. The lignans are therefore probably not biologically available at this site. It is unlikely that plant lignan glycosides are absorbed, because there are to the best of our knowledge no glycosidases present in human (or pig) organs except in the gut. It is probable that the lignan glycosides behave like oestrogen conjugates, which are not absorbed from the intestine without previous hydrolysis (Adlercreutz et al. 1976). In accordance, the majority of the conjugated ileal lignans, in particular, were plant lignans in contrast to the caecum, where the lignans were mostly mammalian. This confirmed the need for microbial action to convert the plant lignans into the biologically active mammalian lignans (Borriello et al. 1985). The low concentration of mammalian lignans in the ileum was in agreement with the very low urinary excretions of mammalian lignans from ileostomy patients consuming rye breads as described by Pettersson et al. (1996). Overall, the intestinal concentrations of lignans were highest in the samples derived from the pericarp-testa diet, which had the highest content of dietary lignans.

Using the $\mathrm{Cr}_{2} \mathrm{O}_{3}$ marker, it was possible to estimate the quantitative recoveries of lignans in the intestinal segments. The recovery of dietary lignans in the ileum was considerably higher than the intake of lignans. Axelson \& Setchell (1981) showed that a proportion of lignans absorbed from the intestinal lumen of rats were re-excreted with the bile via the enterohepatic circulation. Lignans are closely related to phenolic oestrogens (Adlercreutz \& Mazur, 1997), and Adlercreutz and co-workers have studied the enterohepatic circulation of oestrogens in human subjects (Adlercreutz, 1970; Adlercreutz \& Martin, 1980). They estimated that about $50 \%$ of the conjugated oestrogens in the liver are excreted into the bile and re-enter the human intestine (Adlercreutz, 1970; Adlercreutz \& Martin, 1980). It seems likely, therefore, that enterohepatic circulation of lignans explains at least part of the high recoveries of dietary lignans in the ileum of pigs. As the ileal lignans were mostly plant lignans, the questions remain whether the lignans entering the enterohepatic circulation are plant lignans absorbed as such and/or absorbed mammalian lignans are re-converted into plant lignans before re-excretion into the small intestine. Plant lignans were recovered in the urine of ileostomy patients (Pettersson et al. 1996) suggesting that these are absorbed as such, whereas the re-conversion of lignans may be supported by the study from Nose et al. (1992) which indicated that the lignans arctiin and tracheloside were re-methylated in the liver of rats.

However, two to three times as much lignan as had been ingested was recovered in the faeces of the pigs fed the highfibre diets (whole rye, pericarp-testa and aleurone). In contrast, only half of the ingested lignans from the lowdietary-fibre endosperm diet were recovered in faeces. The high faecal recoveries of dietary lignans are in agreement with previous results. Adlercreutz \& Mazur (1997) observed higher urinary excretion of lignans compared with the intake in women consuming rye breads, and Rickard et al. (1996) showed that the urinary excretion of lignans was five times higher in rats fed a linseed diet compared with rats fed the same amount of Seco determined in the diet. These observations suggest that the amount of lignans in the diets may be underestimated, either because not all precursors or intermediary forms are identified or because not all of the identified precursors are measured with the current methodology. The difference between diets in recovery of dietary lignans indicated an effect of dietary characteristics on the determination of lignans in food material. Dietary lignans may be underestimated if they are protected by the surrounding plant cell wall (which comprise the majority of dietary fibre in cereals) or by another part of the food matrix, and the acid hydrolysis applied during analysis is not strong enough to open up the plant material. However, the lignans not included during analysis of the diet may be detected in the ileum samples where the majority of the food matrix has been digested and the microbial degradation of dietary fibre is initiated. Dietary lignans may also be underestimated due to the presence of particular lignan structures, e.g. the tan polymer isolated from flaxseed by Bakke \& Klosterman (1956) which required methoxide treatments to liberate Seco or lignans polymers as suggested by Anderegg \& Rowe (1974), which may escape analytical determination and still be degraded and available in the body.

In the large intestine, only the unconjugated lignans were determined, assuming that the active fermentation of the caecum would deconjugate the majority of lignans from this site onwards. As the content of lignans in the diet may be underestimated, the recovery of lignans in the large intestine were also calculated relative to the ileal lignans. The recoveries of ileal lignans showed that only $21-42 \%$ of ileal lignans were recovered in the caecum, and thus indicated that most of the ileum lignans were absorbed in the low 
ileum and in the caecum. The daily disappearance of lignans from this part of the intestine amounted to 22, 118, 34 and $6 \mu \mathrm{mol} / \mathrm{d}$ for the whole rye, pericarp-testa, aleurone and endosperm diets respectively. In comparison, the daily urinary excretion of lignans in women ingesting rye breads in the aforementioned study by Adlercreutz \& Mazur (1997) was about $1.9-7.3 \mu \mathrm{mol} / \mathrm{d}$, and values up to 17 or $48 \mu \mathrm{mol} / \mathrm{d}$ have been reported as daily urinary lignan excretion in human subjects consuming vegetarian or high-lignan diets (Adlercreutz et al. 1981; Lampe et al. 1994). As evident in Table 5, the amount of lignans excreted with faeces is higher in pigs than in human subjects, because the pigs pass larger amounts of stool. If calculated relative to intake of dietary fibre, the pigs excreted approximately 0.05, 0.12, 0.07 and $0.01 \mu \mathrm{mol} / \mathrm{g}$ dietary fibre ingested from the whole rye, pericarp-testa, aleurone and endosperm diets respectively. From our studies (Adlercreutz et al. 1986, 1995a) on human subjects we calculated that 0.09 and $0.17 \mu \mathrm{mol}$ lignans were excreted per g dietary fibre ingested by omnivorous and vegetarian subjects respectively, and thus the level of faecal excretion of lignans relative to dietary fibre intake appeared to be similar in pigs and human subjects.

\section{Fermentation and metabolism of rye lignans}

The diets used in the present study behaved quite differently in the large intestine of pigs as a result of differences in dietary fibre characteristics (Glits $\varnothing$ et al. 1998). The pericarp-testa dietary fibre was barely degraded, whereas endosperm dietary fibre was extensively degraded in the caecum and aleurone dietary fibre was degraded to nearly the same extent but at a slower rate. These differences in fermentation pattern lead to considerable variations in $\mathrm{pH}$, transit time, bulking effect and production of short-chain fatty acids between the rye-bread diets (Glits $\varnothing$ et al. 1998). Despite these differences in colon fermentation, however, the recovery of ileal lignans in the large intestine was largely similar between diets and thus an effect of colon fermentation on the utilisation of lignans was not evident. The current study showed that degradation of plant cell walls is not a prerequisite for lignan metabolism, as the pericarp-testa lignans were converted from plant to mammalian lignans despite the very low degradability of dietary fibre in this diet.

In conclusion, the present study showed that the concentration of lignans in intestinal samples and the amount of lignans disappearing from the intestinal tract was determined by the content of plant lignans in the diet. Most of the rye lignans seemed to disappear in the low ileum and in the caecum, and in this segment the disappearance of lignans was about twenty times higher from the pericarp-testa diet compared with the endosperm diet, and about three to five times higher compared with the whole rye and aleurone diets. Lignan liberation and metabolism in the colon was similar between diets despite large variations in colon fermentation patterns.

\section{Acknowledgements}

The author W. M. M. thanks the Graduate School of Steroid Research for scholarship. The authors appreciate Dr Mariko Uehara's assistance in the statistical analysis. We also thank
Inga Wiik (analysis of faeces) and Ritva Takkinen (GCMS) for skilful technical assistance during this work.

\section{References}

Adlercreutz H (1970) Oestrogen metabolism in liver disease (Review). Journal of Endocrinology 46, 129-163.

Adlercreutz H (1995) Phyto-oestrogens, epidemiology and a possible role in cancer prevention. Environmental Health Perspectives 103, 103-112.

Adlercreutz H, Fotsis T, Bannwart C, Hämäläinen E, Bloigu S \& Ollus A (1986) Urinary estrogen profile determination in young Finnish vegetarian and omnivorous women. Journal of Steroid Biochemistry 24, 289-296.

Adlercreutz H, Fotsis T, Heikkinen R, Dwyer JT, Goldin B, Gorbach SL, Lawson AM \& Setchell KDR (1981) Diet and urinary excretion of lignans in female subjects. Medical Biology 59, 259-261.

Adlercreutz H, Fotsis T, Kurzer MS, Wähälä K, Mäkelä T \& Hase T (1995a) Isotope dilution gas chromatographic-mass spectrometric method for the determination of unconjugated lignans and isoflavonoids in human faeces, with preliminary results in omnivorous and vegetarian women. Analytical Biochemistry 225, 101-108.

Adlercreutz H \& Martin F (1980) Biliary excretion and intestinal metabolism of progesterone and oestrogens in man. Review. Journal of Steroid Biochemistry 13, 231-244.

Adlercreutz H, Martin F, Pulkkinen M, Dencker H, Rimer U, Sjoberg NO \& Tikkanen MJ (1976) Intestinal metabolism of oestrogens. Journal of Clinical Endocrinology and Metabolism 43, 497-505.

Adlercreutz H \& Mazur W (1997) Phyto-oestrogens and western diseases. Annals of Medicine 29, 95-120.

Adlercreutz H, van der Wildt J, Kinzel J, Attalla H, Wähälä K, Mäkelä T, Hase T \& Fotsis T (1995b) Lignan and isoflavonoid conjugates in human urine. Journal of Steroid Biochemistry and Molecular Biology 52, 97-103.

Anderegg RJ \& Rowe JW (1974) Lignans, the major component of resin from Araucaria angustifolia knots. Holzforchung 28, 171175.

Axelson M \& Setchell KDR (1981) The excretion of lignans in rats - evidence for an intestinal bacterial source for this new group of compounds. FEBS Letters 123, 337-342.

Ayres DC \& Loike JD (1990) Lignans. Chemical, Biological and Clinical Properties. Cambridge: Cambridge Univeristy Press.

Bach Knudsen KE (1997) Carbohydrate and lignin contents of plant materials used in animal feeding. Animal Feed Science and Technology 67, 319-338.

Bach Knudsen KE, Jensen BB \& Hansen I (1993) Digestion of polysaccharides and other major components in the small and large intestine of pigs fed diets consisting of oat fractions rich in $\beta$-D-glucan. British Journal of Nutrition 70, 537-556.

Bakke JE \& Klosterman HJ (1956) A new diglucoside from flaxseed. Proceedings of the North Dakota Academy of Science 10, 18-22.

Bingham SA, Atkinson C, Liggins J, Bluck L \& Coward A (1998) Phyto-oestrogens - where are we now? British Journal of Nutrition 79, 393-406.

Borriello SP, Setchell KDR, Axelson M \& Lawson AM (1985) Production and metabolism of lignans by the human faecal flora. Journal of Applied Bacteriology 58, 37-43.

Cummings JH \& MacFarlane GT (1991) The control and consequences of bacterial fermentation in the human colon. Journal of Applied Bacteriology 70, 443-459.

Eraso F \& Hartley RD (1990) Monomeric and dimeric phenolic 
constituents of plant cell wall - possible factors influencing wall biodegradability. Journal of the Science of Food and Agriculture 51, 163-170.

Glits $\varnothing$ LV \& Bach Knudsen KE (1999) Milling of whole grain rye to obtain fractions with different dietary fibre characteristics. Journal of Cereal Science 29, 89-97.

Glits $\varnothing$ LV, Brunsgaard G, Højsgaard S, Sandström B \& Bach Knudsen KE (1998) Intestinal degradation in pigs of rye dietary fibre with different structural characteristics. British Journal of Nutrition 80, 457-468.

Knight DC \& Eden JA (1996) A review of the clinical effects of phyto-oestrogens. Obstetrics and Gynecology 87, 897-904.

Lampe JW, Martini MC, Kurzer MS, Adlercreutz H \& Slavin JL (1994) Urinary lignan and isoflavonoid excretion in premenopausal women consuming flaxseed powder. American Journal of Clinical Nutrition 60, 122-128.

Mazur WM \& Adlercreutz H (1998) Naturally occuring oestrogens in food. Pure and Applied Chemistry 70, 1759-1776.

Mazur WM, Duke JA, Wähälä K, Rasku S \& Adlercreutz H (1998) Isoflavanoids and lignans in legumes, nutritional and health aspects in the human. Journal of Nutritional Biochemistry $\mathbf{9}$, 193-200.

Mazur W, Fotsis T, Wähälä K, Ojala S, Salakka A \& Adlercreutz H (1996) Isotope dilution gas chromatographic-mass spectrometric method for the determination of isoflavonoids, coumesterol and lignans in food samples. Analytical Biochemistry 233, 169-180.

Miller ER \& Ullrey DE (1987) The pig as a model for human nutrition. Annual Review of Nutrition 7, 361-382.

Murkies AL, Wilcox G \& Davis SR (1998) Clinical review 92 Phyto-oestrogens. Journal of Clinical Endocrinology and Metabolism 83, 297-303.

Nilsson M, Ảman P, Härkönen H, Hallmans G, Bach Knudsen KE, Mazur W \& Adlercreutz H (1997) Content of nutrients and lignans in roller milled fractions of rye. Journal of the Science of Food Agriculture 73, 143-148.

Nose M, Fujimoto T, Takeda T, Nishibe S \& Ogihara Y (1992)
Structural transformation of lignan compounds in rat gastrointestinal tract. Planta Medica 58, 520-523.

Pettersson D, Aman P, Bach Knudsen KE, Lundin E, Zhang J-X, Hallmans G, Härkönen H \& Adlercreutz H (1996) Intake of rye bread by ileostomists increases ileal excretion of fibre polysaccharide components and organic acids but does not increase plasma or urine lignans and isoflavanoids. Journal of Nutrition 126, 1594-1600.

Rickard SE, Orcheson LJ, Seidl MM, Luyengi L, Fong HHS \& Thompson LU (1996) Dose-dependent production of mammalian lignans in rats and in vitro from the purified precursor secoisolariciresinol diglycoside in flaxseed. Journal of Nutrition 126, 2012-2019.

Rowan AM, Moughan PJ, Wilson MN, Maher K \& Tasman-Jones C (1994) Comparison of the ileal and faecal digestibility of dietary amino acids in adult humans and evaluation of the pig as a model animal for digestion studies in man. British Journal of Nutrition 71, 29-42.

Schürch AF, Lloyd LE \& Crampton EW (1950) The use of chromic oxide as an index for determining the digestibility of a diet. Journal of Nutrition 50, 628-636.

Setchell KDR \& Adlercreutz H (1988) Mammalian lignans and phyto-oestrogens. Recent studies on their formation, metabolism and biological role in health and disease. In Role of the Gut Flora in Toxicity and Cancer, pp. 315-345 [IR Rowland, editor]. London: Academic Press.

Setchell KDR, Borriello SP, Gordon H, Lawson AM, Harkness R, Morgan DM, Kirk DN, Adlercreutz H, Anderson LC \& Axelson M (1981) Lignan formation in man - microbial involvment and possible roles in relation to cancer. Lancet 2, 4-7.

Sfakianos J, Coward L, Kirk M \& Barnes S (1997) Intestinal uptake and biliary excretion of the isoflavones genistein in rats. Journal of Nutrition 127, 1260-1268.

Stevens C E, Argenzio R A, Roberts M C (1986) Comparative physiology of the mammalian colon and suggestions for animal models of human disorders. Clinical Gastroenterology 15, 763785 . 